\title{
The Topological Optimization and the Design for Additive Manufacturing of a Steering Knuckle for Formula SAE Electric Vehicle
}

\author{
Theodor-Florian Zach ${ }^{1}$, and Mircea-Cristian Dudescu ${ }^{2 *}$ \\ ${ }^{1}$ Technical University of Cluj-Napoca, Advanced Techniques in Automotive Engineering, Blvd. \\ Muncii no. 103-105, Cluj-Napoca, Romania \\ ${ }^{2}$ Technical University of Cluj-Napoca, Department of Mechanical Engineering, Blvd. Muncii no. \\ 103-105, Cluj-Napoca, Romania
}

\begin{abstract}
Formula Student represents the main motorsport activity for future professionals during their academic preparation. There is intensive migration from the prototypes with an internal combustion engine to electrical vehicles. The challenge of electric vehicles is the weight of the batteries which has to be compensated. The Topological Optimization process represents a method of removing volume and mass of the component (elements of mesh) with the aid of the discretization allowed by the finite element method (FEM) until a mass or stress constraint is attained. The results come in a complex shape, the material being kept only in the stressstrain directions. The manufacturing process is usually as complex, being employed high complexity technologies such as Selective Laser Melting (SLM). Improved strength-to-weight ratio materials are to be considered to obtain the most performant design of a specific component. The present paper presents the topological optimization process of the steering knuckle for the Formula Student electric vehicle of ART-TU Team of Technical University of Cluj-Napoca. It means that the part is simulated and optimized through Ansys Static Structural and there is done post-processing of the component along with Data Validation. The conclusions consist of the viability of the Topological Optimization process when designing complex components for performance automotive.
\end{abstract}

\section{Introduction}

A Topological Optimization procedure is a means of optimizing the structure of a component to achieve the most favorable strength-to-weight ratio. The method consists of the discretization of the CAD model and removing by iterations elements that are redundant into the structural strength of the part. The constraints consist of the mass, volume, or stress limit which is imposed on the optimized design. [1]

\footnotetext{
* Corresponding author: mircea.dudescu@,rezi.utcluj.ro
} 


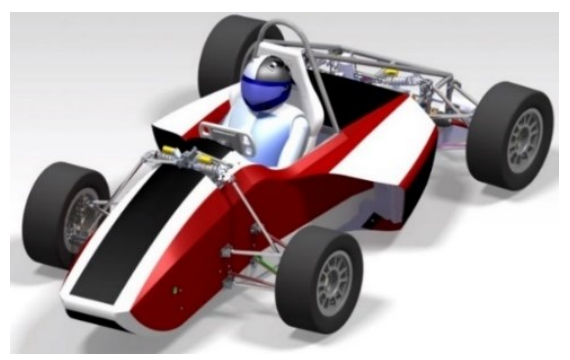

Fig. 1. ART-TU Formula Student Mono-Post

Formula SAE represents a competition made by Formula SAE International Organization from the USA where students from around the world develop a fully functional racetrack prototype. The design of the steering knuckle was carried out for the Formula SAE vehicle developed by the ART-TU team from Technical University of Cluj-Napoca, the prototype which can be observed in Fig. 1. It is an electric vehicle (EV), where the overall weight is a challenge due to the battery pack. The main challenge in design is to conduct an optimization process on components to have a lightweight design, keeping the functionality to the same standards. [2]

The methodology for the paper is the complete parametrization and enabling the topdown design methods in CATIA V5. After the design phase, there are carried out FEM static simulations, including analytical calculus of loads, materials assignment. The topological optimization process is done through the Ansys Topological Optimization module and it is post-processed with Ansys SpaceClaim. The Simulations are to be discussed in Chapter 3.1 and the feasibility of the design and simulation methods are concluded.

\section{Materials and Methods}

\subsection{Materials}

There were distinguished two cases of manufacturing technologies (and different materials for this application). At first, there is considered a machined part. In this case, there was found that aluminum is the most suitable material for the machined component. The study case has taken as an option the AA 7075. It is used widely in the automotive and aerospace engineering fields due to its ratio of strength in comparison with weight [3].

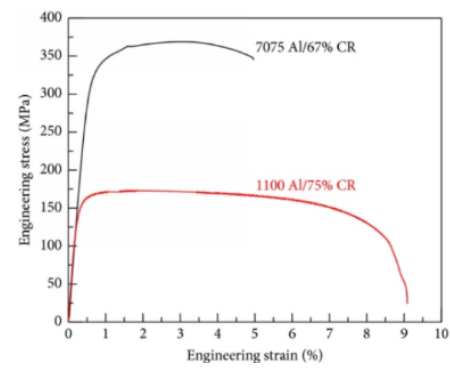

Fig 2. Tensile Diagram for AA-7075 [4]

The mechanical characteristics of AA 7075 are presented in Table 1. Its density is higher than pure aluminum $\left(2810 \mathrm{~kg} / \mathrm{m}^{3}\right.$ vs $\left.2700 \mathrm{~kg} / \mathrm{m}^{3}\right)$ due to alloying elements, but the tensile strength is significantly higher than ordinary AA 1050 which is widely used for ordinary parts manufactured from aluminum (375 $\mathrm{MPa}$ in comparison to $110 \mathrm{MPa}$ ) as one may notice 
in Fig 2. The tensile diagram shows that the profile of the AA7075 has a smaller strain until rupture, but significantly high yield strength compared to the ordinary AA 1050. [5]

Table 1. The Mechanical Properties of AA 7075 T6 [6]

\begin{tabular}{|l|c|}
\hline Mechanical Property & Value \\
\hline Density [kg/m $\left.{ }^{3}\right]$ & 2810 \\
\hline Yield Strength [MPa] & 375 \\
\hline Modulus of Elasticity [GPa] & 71.7 \\
\hline Poisson Ratio [-] & 0.33 \\
\hline
\end{tabular}

For Selective Laser Melting, there is a limited supply of materials. There are several stainless-steel alloys (widely used 306L), titanium alloys (Ti-6Al-4V, Ti-6Al-Nb), and Inconel 718 or Hastalloy (nickel-based alloys). Due to the strength to weight ratio needed for this application, the material chosen was Ti-6Al-4V grade 5, a common titanium alloy used in automotive and aerospace industry and in some cases in medical applications. In Table 2 are enlisted the characteristics of the material as SLM printed samples. [6]

Table 2. Mechanical Properties of Ti-6Al-4V Grade 5 alloy in form of SLM specimens [7]

\begin{tabular}{|l|c|}
\hline Mechanical Property & Value \\
\hline Density $\left[\mathrm{kg} / \mathrm{m}^{3}\right.$ ] & 4430 \\
\hline Yield Strength [MPa] & $1098 \pm 45$ \\
\hline Modulus of Elasticity [GPa] & $109 \pm 6.3$ \\
\hline Poisson Ratio [-] & 0.342 \\
\hline
\end{tabular}

In comparison, with AA 7065 T6 presented previously, the Titanium alloy has a density of $4430 \mathrm{~kg} / \mathrm{m}^{3}$ (it is considered $100 \%$ relative density for the simplification) which is roughly 1.5 times more than aluminum alloy chosen for the machined variant of the steering knuckle. The Yield Strength is significantly increased (from $375 \mathrm{MPa}$, to $1090 \mathrm{MPa}$ ), which is 1.75 times higher. [7]

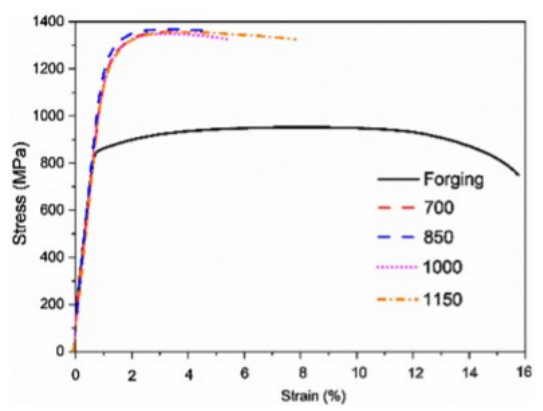

Fig. 3 Tensile characteristics of specimens obtained by SLM and Forging Ti-6Al-4V alloy [8]

In Fig. 3, one may notice that all the samples of Ti-6Al-4V printed on SLM with $250 \mathrm{~W}$ and different scanning speeds are superior to the forged-based samples. This fact is explainable because the printing includes a secondary complex heat treatment onto the SLMbased samples. The forged-based material is around $880 \mathrm{MPa}$, while SLM based part has a yield strength of $1250 \mathrm{MPa}$ for $275 \mathrm{~W}$ laser power and $850 \mathrm{~mm} / \mathrm{s}$ scanning speed. 
Alternatively, the printed parts are subjected to stress-relief sonic or heat-treatments to eliminate the residual stresses and re-crystallization annealing for having an equiaxed grain structure. [9]

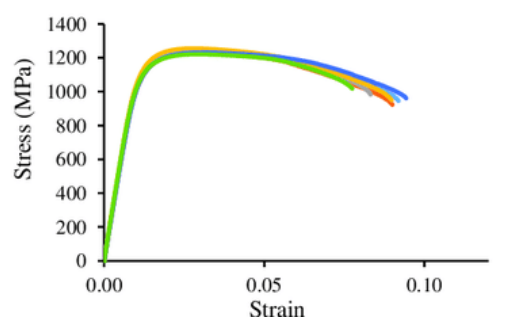

Fig. 4.Tensile Curve for Ti-6Al-4V SLM Samples [7]

The materials are defined in Ansys with the properties defined in Table 1 and Table 2. in the Engineering Data of Ansys structural simulation, the material assignment being one of the steps of pre-processing FEM simulations.

\subsection{Design of the Component}

The design of the part is made by Boolean Design Method using intense parametrization of dimensional measurements. The component is designed for a Formulae SAE EV. Taking into consideration this aim of the part, the design should be flexible to be customized and accessible to be adapted to different configurations of the concept car, using intense parametrization and top-down design.

The steering knuckle (upright) represents a key component linked to suspension, steering, braking, and powertrain systems. It is a static part that is among the mobile parts. The stiffness of the part needs special attention in the design phase, due to its influence upon the wishbones of the suspension, which are dynamically loaded onto a regular driving routine. It links as well as the steering system through tie rods. The braking phenomenon includes intense vibrations into the vehicle. Nevertheless, the rotation of the wheel is driven by the wheel hub which is mounted with the aid of bearing couplings onto the steering knuckle. There are highlighted all the links presented before in

Fig. 5 [10].

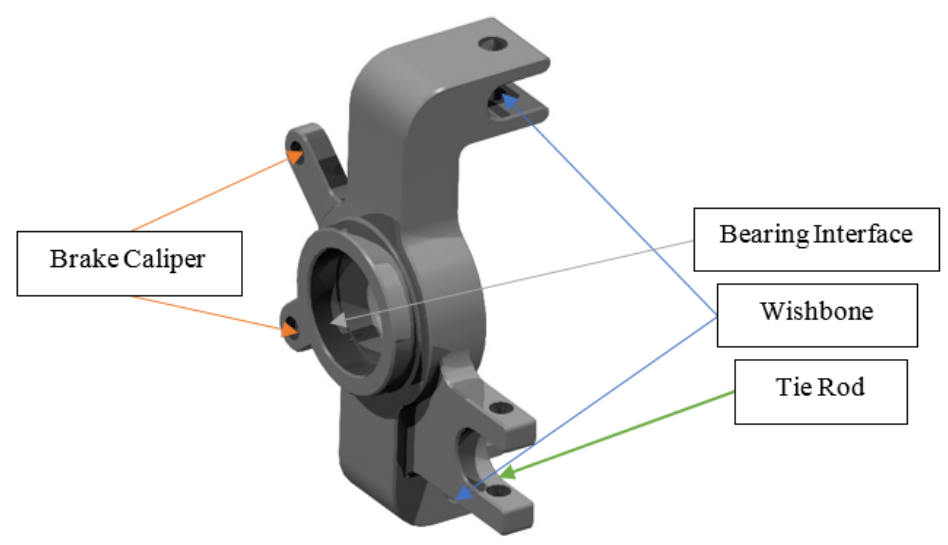

Fig. 5. The Design of the Steering Knuckle 
The Boolean Design Method relies upon a specific procedure that makes use of defining different bodies with a single feature. The final product is represented by multiple Boolean operations such as Add, Remove, Intersect, Assemble, or Union Trim.

\subsection{The Boundary Conditions and FEM Pre-Processing}

The Boundary Conditions for steering and suspension systems in this simulation are considered in Table 3. There is considered a similar vehicle developed by California Polytechnic State University from San Luis, California for a Formula SAE Vehicle. [11]

Table 3. Forces for the Suspension System on Steering Knuckle [11]

\begin{tabular}{|l|l|}
\hline Force [N] & Value \\
\hline Upper Wishbone Left & 929.8 \\
\hline Upper Wishbone Right & 892.8 \\
\hline Tie Rod & 2318.5 \\
\hline Lower Wishbone Left & 1720.8 \\
\hline Lower Wishbone Right & 2258.4 \\
\hline Pull/Push Rod & 4239 \\
\hline
\end{tabular}

For the Braking System, there was considered a calculation based on the weight of the vehicle and the deceleration needed for the vehicle to fulfil the regulation rule to lock all 4 wheels, resulting in the force on the brackets of $2207 \mathrm{~N}$. The calculus was carried out in Mathcad and based on the formulas presented in [12] and on the regulation of Formula Student (FSAE). [13]

$$
\begin{gathered}
W=m \cdot g=4000 \mathrm{~N} \\
F_{\max }=W \cdot \mu_{p}=2207 \mathrm{~N}
\end{gathered}
$$

Where: $W$-Gravity of the vehicle $[\mathrm{N}]$;

$m$-mass of the vehicle $[\mathrm{kg}]$;

g-gravitational acceleration $\left(9.81 \mathrm{~m} / \mathrm{s}^{2}\right)$.

$F_{\max }$ - Maximum braking force [N]

$\mu_{\mathrm{p}}-$ Friction coefficient $(0.55)[-]$

The bearing loads (interface with the power-train system) were calculated. The approximate weight was considered as $400 \mathrm{~kg}$ for the entire vehicle and the weight distribution was considered $80 \%$ for the front wheels during the braking of the vehicle and steering with a lateral force of $1.7 \mathrm{G}$ (values from the design recommendations of FSAE competition, which is $1.5 \mathrm{G}$ and a $0.2 \mathrm{G}$ addition as a safety factor). The parameters were calculated with the formulas (3) and (4), the axial load and $\mathrm{F}_{\mathrm{a}}=6800 \mathrm{~N}$ and radial load $\mathrm{F}_{\mathrm{r}}=$ 1600 N. [14] [15]

$$
\begin{gathered}
F_{r}=0.4 \cdot W=1600 \mathrm{~N} \\
F_{a}=1.7 \cdot W=6800 \mathrm{~N}
\end{gathered}
$$

Where: $F_{\mathrm{r}}-$ radial force $[\mathrm{N}]$

$F_{\mathrm{a}}-$ axial force $[\mathrm{N}]$

The Boundaries are applied similarly on the coordinate systems like the ones defined in the Design Phase of the Steering Knuckle. One may see in Fig. 6 that there were defined 
coordinate systems for the central bearing, where axial and radial forces on the bearing are applied.

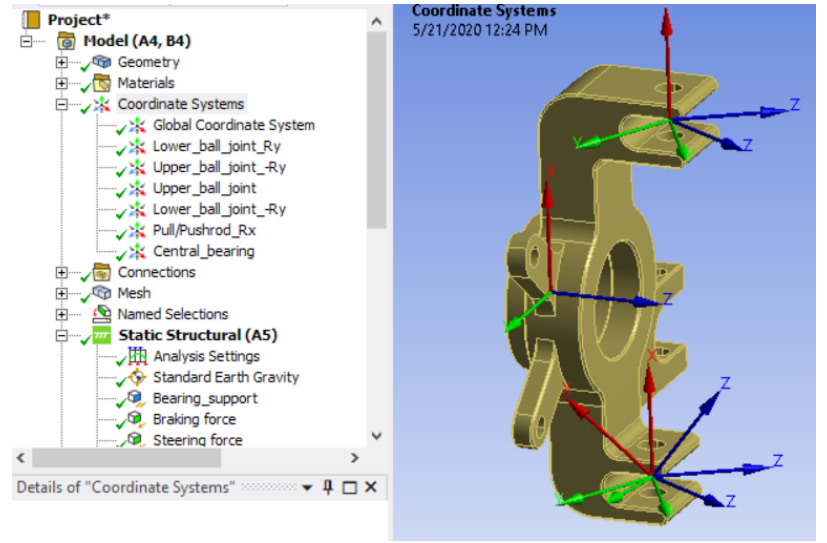

Fig. 6. The Reference Coordinate Systems on the Steering Knuckle

In Fig. 7 a), there were measured the upper wishbone angle, which is around $46^{\circ}$, which was set up equally for the arms at $23^{\circ}$, to have a uniform distribution of forces through the upper wishbone of the suspension. The lower suspension angle was considered roughly $41.3^{0}$ with a $20.75^{\circ}$ between the lower arms of the suspension and the neutral line as one may notice in Fig. 7. b).

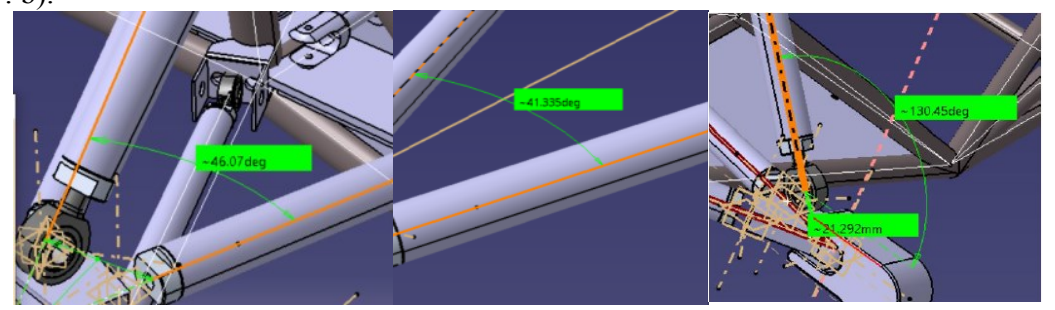

(a)

(b)

(c)

Fig. 7. Suspension Angles: a) Lower Wishbone; b) Upper Wishbone; c) Pull/Push Rod.

The pull/push rod was considered on the lower wishbone due to vehicle dynamics and calculated within the Formula Student Team of Technical University of Cluj-Napoca, with an angle of roughly $50^{\circ}$ angle difference from the horizontal plane as measured in Fig. 7. c).

Into a FEM simulation, the degrees of freedom should be limited. Because of the dynamic movement of the entire axle, there was considered a simplification. The central hole of the steering knuckle on which bearings and wheel hub are mounted was considered fixed because the wheel should maintain its relative position to the steering knuckle whatever bump is approached. The orientation of forces is presented in Fig. 8. with the values presented in this Table 3, and the fixed support that was considered. 


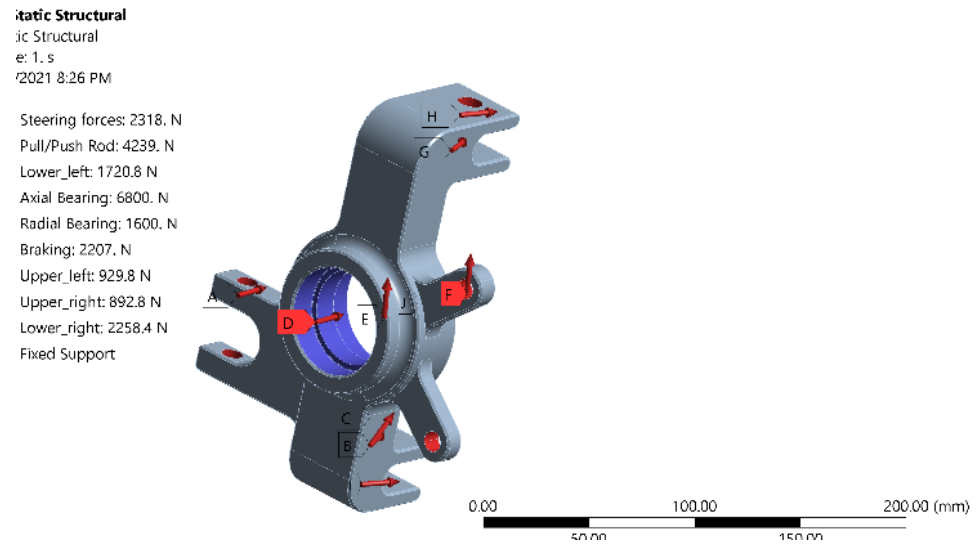

Fig. 8. The Boundary Conditions of the Simulation

\subsection{Topological Optimization for SLM based Design (Organic-Shape Design)}

The Topological Optimization consists of the computerized processing of the part with the loads applied on it and eliminating elements from the mesh, implicitly from the part to reduce mass. The excluded area are the couples where boundary conditions are applied and results come in complex irregular shapes such as Fig. 9 shows.

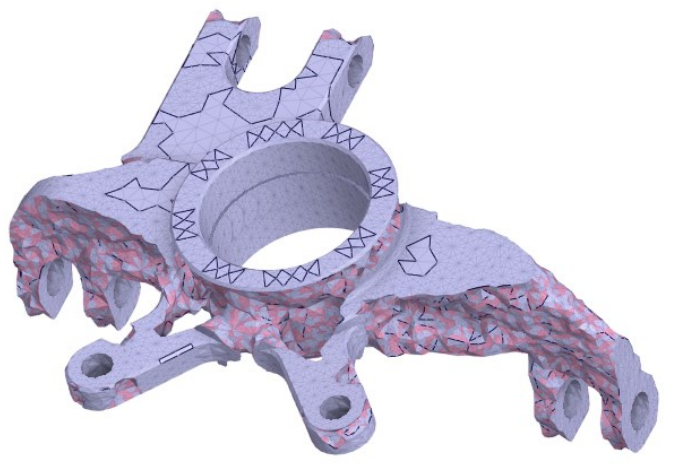

Fig. 9. The Topological Optimization Result (Uncleaned Version)

Through SLM those areas will suffer in dimensional accuracy and post-processing machining processes are needed for the functional areas presented in Fig. 8 and finishing treatments such as sandblasting could be employed. To ensure the depth of cut in this case and the shrinkage of the part during cooling phase of SLM, the part will be scaled with $1 \%$. The criterion of optimization is the mass reduction of the component to $40 \%$.

The primary design, the resulted ".stl" from the Topology Optimization of Ansys is relatively rough due to discretization and the algorithm of optimization. which removed unnecessary elements. The part is smoothed and post-processed and then the faceted part is skinned to have a closed volume with fewer surfaces, which can be edited and easier to mesh. After, there were executed Boolean Operations in Ansys SpaceClaim as noticeable in Fig 10 from the Topological Optimized part to have smooth faces in the couplings area (ball joint, 
brake caliper, steering bracket, and bearing). These operations are similar in approach in real life, where the part is post-processed to obtain the functional dimensions, and the tolerances needed. The other advantage is to adjust geometry on the added faces to influence the design, an example being wishbone couplings which can be increased either in diameter or in thickness.
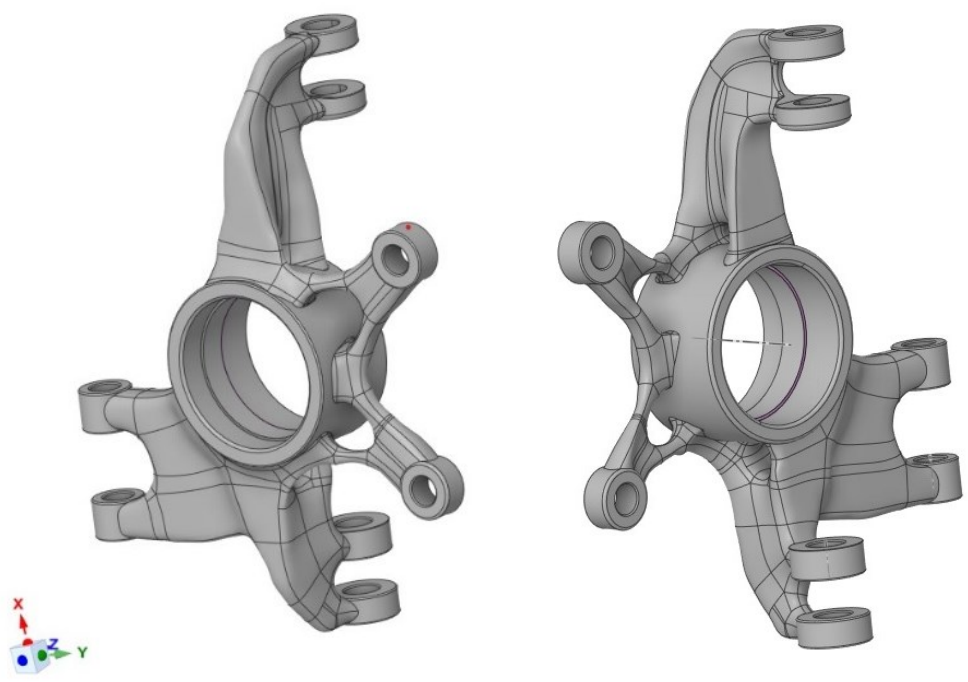

Fig 10. Post-Processing of Topological Optimized Component

A comparative volume design is shown in Fig. 11. The initial part is represented in a semi-transparent volume, which is significantly high visually. The gray part represents the Topological Optimized component. The difference in volume is visible and the parts attached to the suspension wishbones are significantly thinner. The difference in volume reflects the time needed for manufacturing in the case of the SLM variant, the build-up rate of the SLM machines being one of their main specifications.

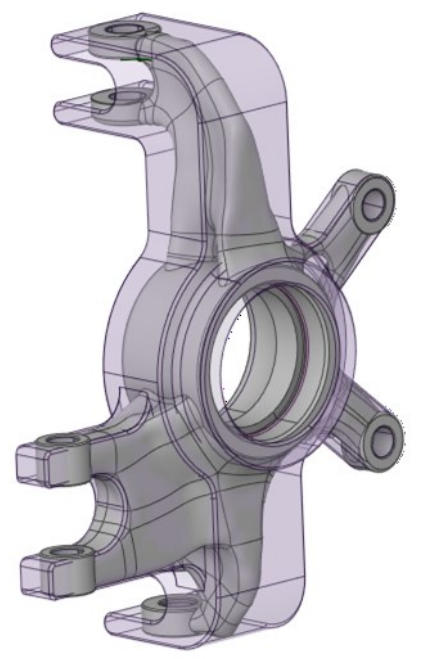

\begin{tabular}{|c|c|}
\hline $\begin{array}{c}\text { Manufacturing } \\
\text { Method }\end{array}$ & Volume \\
\hline Machined & $343.3 \mathrm{~cm}^{3}$ \\
\hline SLM & $157.3 \mathrm{~cm}^{3}$ \\
\hline
\end{tabular}

Fig. 11. Comparison between machined and $3 \mathrm{D}$ printed part 


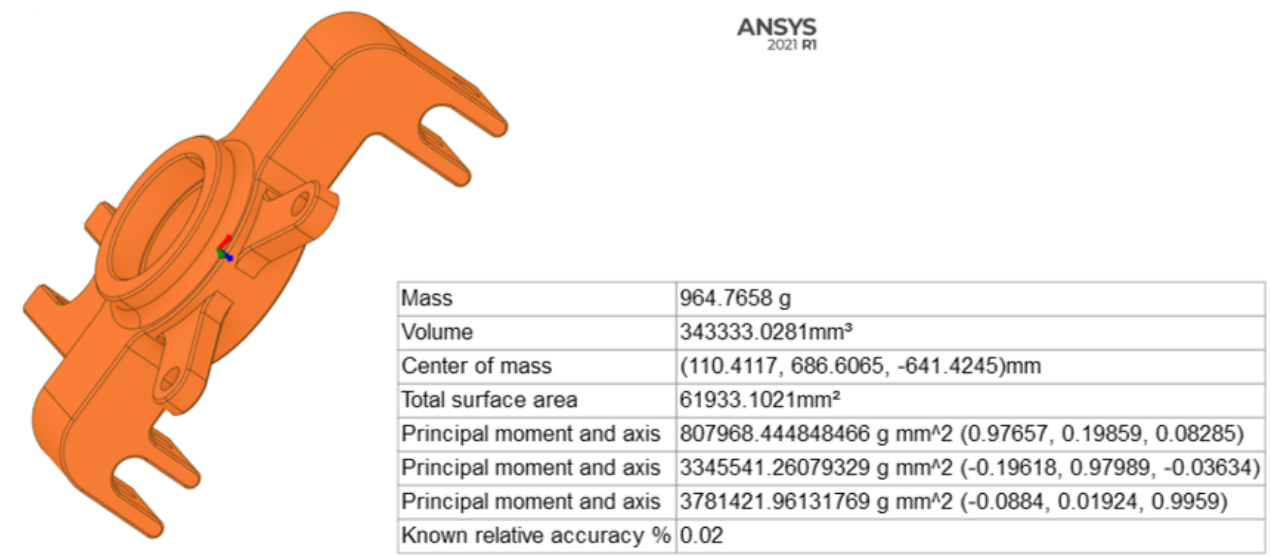

Fig. 12 Mass and Volume Statistics for Machined Component from AA 7075

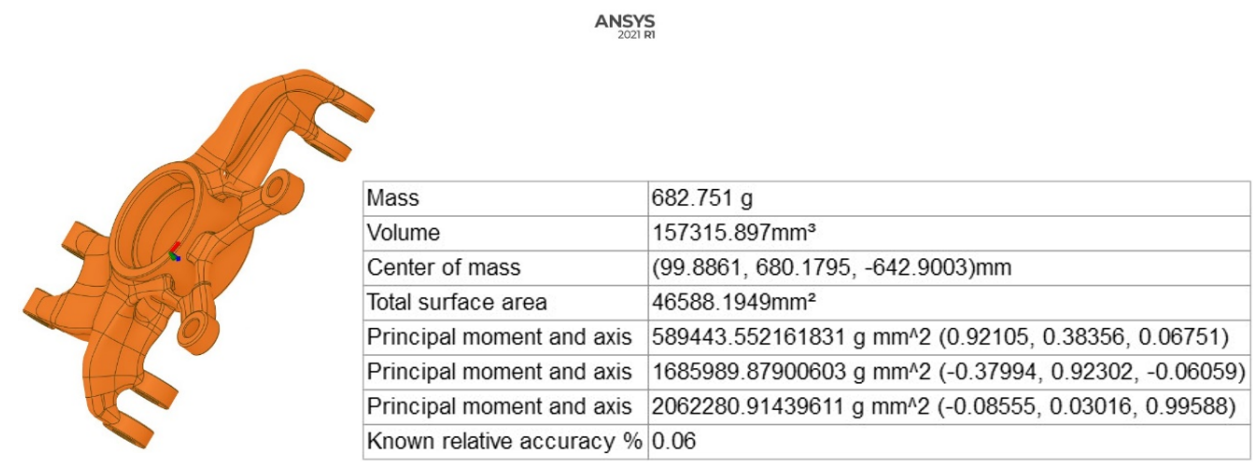

Fig. 13. Mass and Volume Statistics for SLM Component from Ti-6Al-4V

As one may notice in Table 4, the original mass was reduced from $1.51 \mathrm{~kg}$ (if machined from Ti-6Al-4V) or $0.965 \mathrm{~kg}$ (machined from AA 7075 as one may see in Fig. 12) to only $0.683 \mathrm{~kg}$ (visible in Fig. 13) which is about $45.2 \%$ of the original mass, lower than the aluminum machined component with $29.28 \%$, assuming a relative density of the SLM part of $100 \%$, even though this is virtually impossible, but relative density of $99.7 \%$ can be obtained. The aluminum variant manufactured through SLM is the lightest, but it is unfeasible as it will be presented in Section 3.2.

Table 4. Mass Comparison between the Constructive Variants

\begin{tabular}{|l|l|l|}
\hline Manufacturing Method & Material & Mass $(\mathrm{kg})$ \\
\hline Machining & AA-7075 & 0.965 \\
\hline Machining & Ti-6Al-4V & 1.512 \\
\hline Additive Manufacturing & AA-7075 & 0.442 \\
\hline Additive Manufacturing & Ti-6Al-4V & 0.683 \\
\hline
\end{tabular}




\section{Results and Discussions}

\subsection{The Simulation Results and Safety Coefficients}

The simulation was carried out with Ansys Static Structural to assess the design of the steering knuckle machined from AA 7075-T6 considered in Section 2.2 and the boundary conditions presented in Section 2.3.
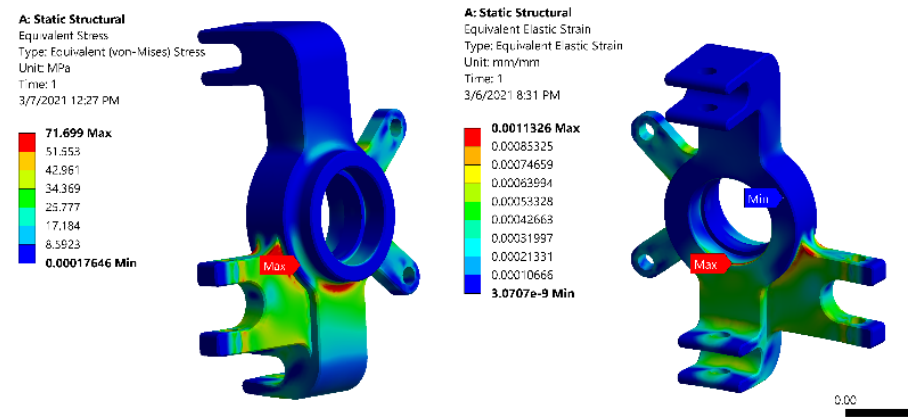

Fig. 14. The Stress and Strain Results of the Static Simulation

In the first place, the stress figures are to be considered. The maximum stress was 71.7 MPa as visible in Fig. 14. They are compared to the Yield Strength of the material (AA-7075 T6 and then assuring that the maximum value of Von-Misses stress does not exceed the yield strength). The equivalent strain has a peak value of $6 \mathrm{e}-5 \mathrm{~mm} / \mathrm{mm}(0.11 \%)$ almost half under the conventional value of $0.2 \%$ as admissible for the elastic domain. For the same component manufactured from Ti-6Al-4V, the strain decreases to $0.076 \%$.
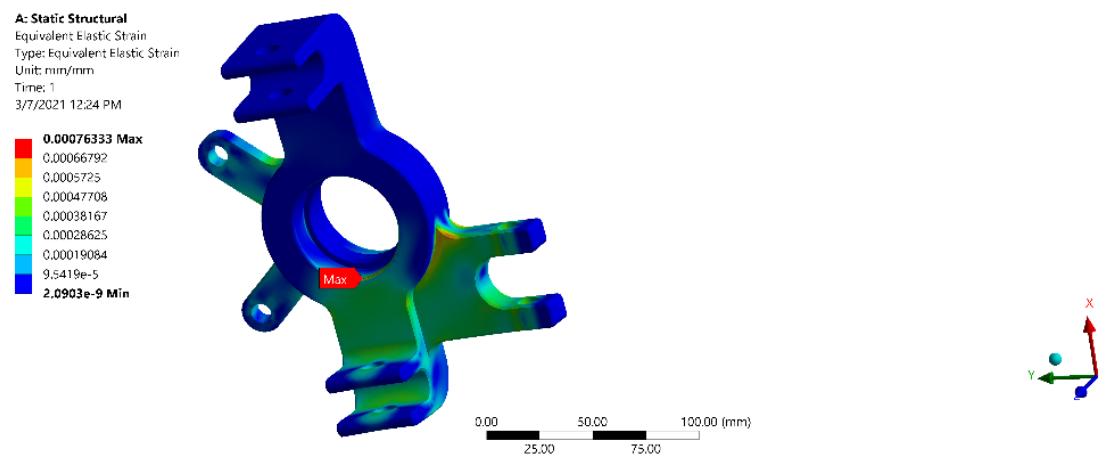

Fig. 15. Strain Values for Machined Ti-6Al-4V Component

For the machined variant, there could be noticed in Fig. 16. the safety factor. In the case of AA 7075, there is a minimal safety coefficient of 5.27, whereas for titanium is almost 10 . This means that the components are over-sized based on the strength needed and optimization should be done. 


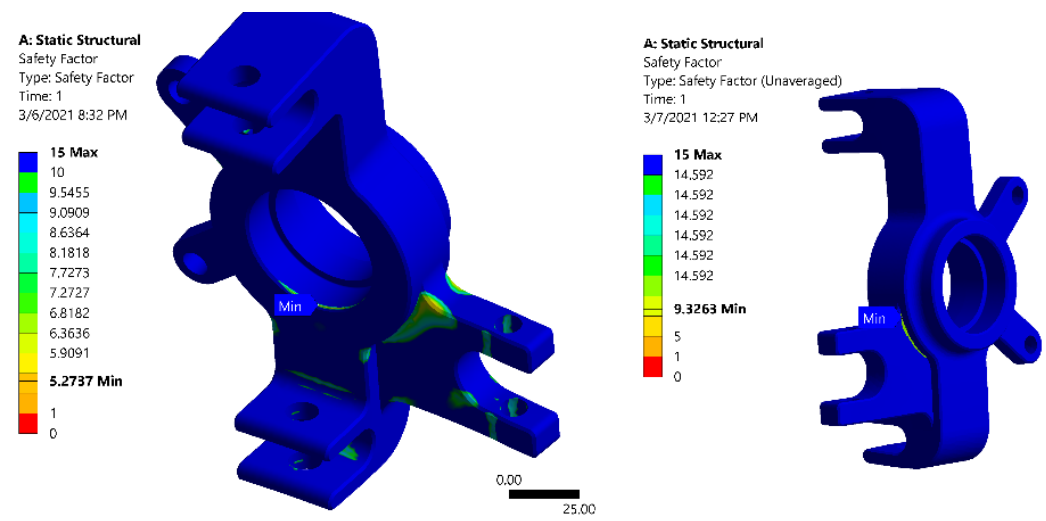

Fig. 16. Safety Factor for Machined Upright from AA 7075-T6 and Ti-6Al-4V

\subsection{Data Validation}

The Topological Optimized part is subjected to FEM simulation with similar loads presented in Section 2.3, to test the optimized part whether it fulfills strength and strain criteria, ensuring that the component works only in the elastic domain. As one may notice in Fig. 17, the maximum stress value (Von-Misses) is around $200.37 \mathrm{MPa}$ and strain to 0.001748 $\mathrm{mm} / \mathrm{mm}(0.175 \%)$ for the Ti-6Al-4V, which is relatively high in comparison and happens at the adjoint faces of the faceted body resulted from topology optimization and the faces added with Boolean Operations in SpaceClaim. The strain value is close to the conventional yield strain $(0.2 \%)$, which means the optimization could not go further.
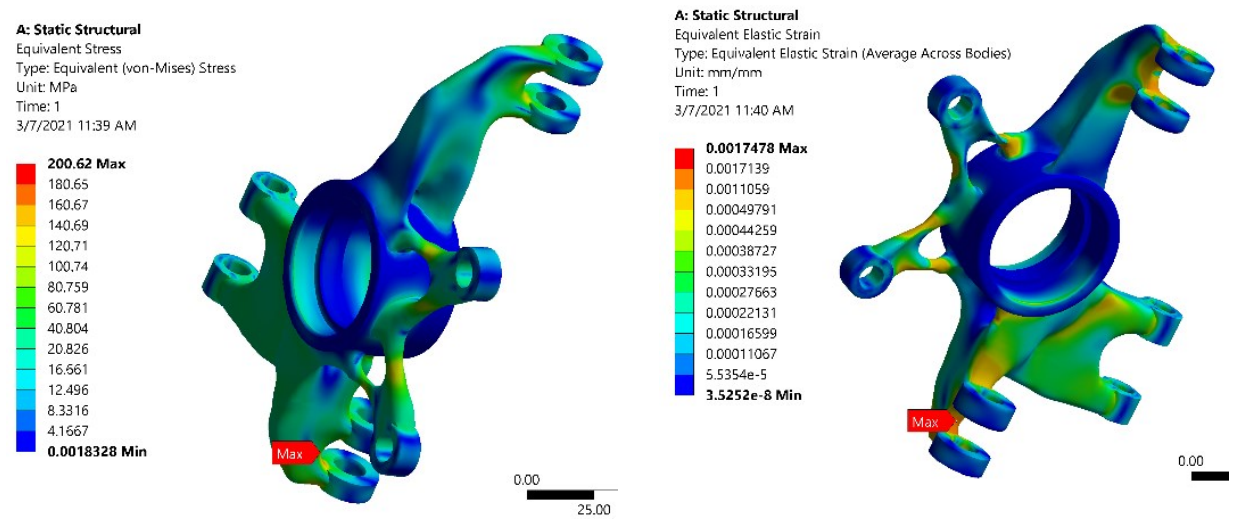

Fig. 17. The Data Validation Stress Simulation and Strain Simulation

By changing the material from AA 7075 to Ti-6Al-4V, the tensile strength is changing from $375 \mathrm{MPa}$ to $1090 \mathrm{MPa}$ as presented in Section 2.1. Nevertheless, SLM manufactured specimens shown a superior strength due to a complex laser heat treatment up to $1090 \mathrm{MPa}$. In Fig. 18, the strain for aluminum peaks at $0.00296 \mathrm{~mm} / \mathrm{mm}(0.296 \%)$, which means that the knuckle made from aluminum by SLM is not feasible, being plastically deformed. 


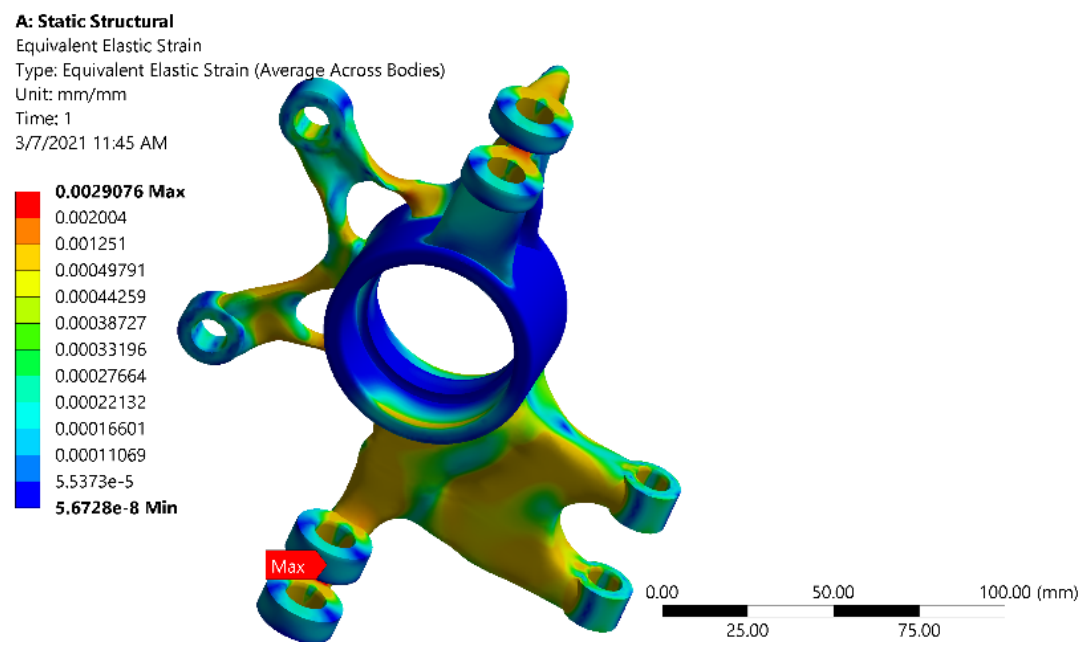

Fig. 18 Strain Results for AA 7075 SLM

The Fig. 19. presents the safety factor for the part considered being manufactured from Ti-6Al-4V with a minimal safety coefficient of 5.47 and from AA 7075 where the minimal value is only 1.87 . This means that the part for titanium is more than 2 , which is satisfactory for this application, whereas for the aluminum variant the chances of breaking the part are quite high, resulting in an unacceptable component in terms of safety. The strain as presented before is the limit condition for the component to maintain its elastic behavior. [16]

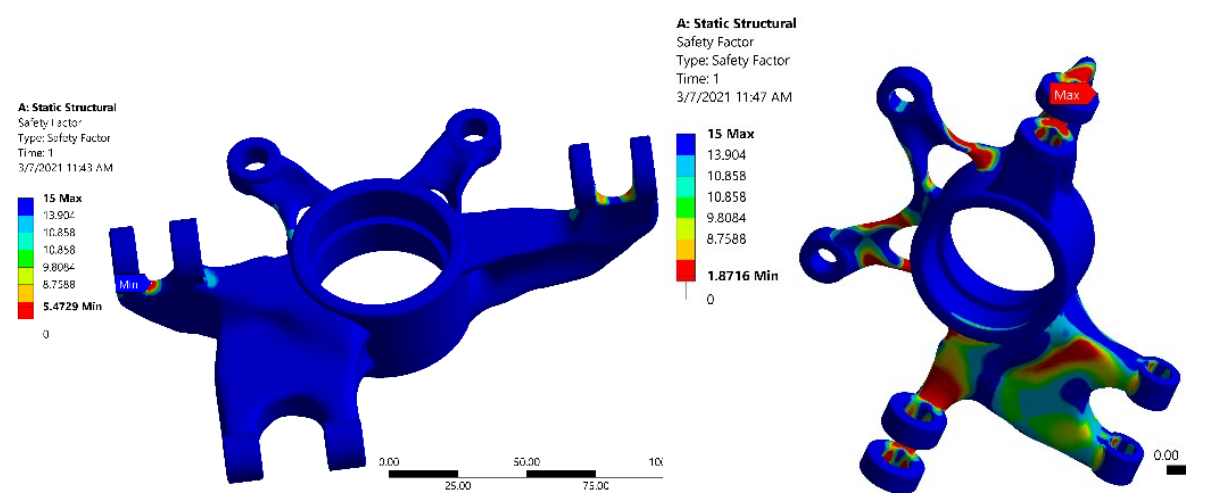

Fig. 19. Safety Factor for 3D printed part from Ti-6Al-4V and AA 7075-T6

\section{Conclusions}

To conclude, the FEM simulations presented in this paper made assess the functionality of the part in the context of an assembly. It is a relatively simple solution to adjust the design concerning the loads which are withstood by the steering knuckle. The Topological Optimization process enables the organic design which is mainly focused on the strength-toweight improving ratio of the component and the 3D printing CAD model, which is the final aim of this paper.

Considering that the part has been reduced through Topological Optimization to only $45.2 \%$ of its original mass (compared for same materials) and $29.28 \%$ of the machined variant from AA 7075, the method proved feasible for the design of such components. In addition, 
the safety coefficient is increased with 3.06\% (comparing the unoptimized AA 7075 and the optimized Ti-6Al-4V design variants), the strain being the only limitation for further optimization. For a Formula SAE electric vehicle, such reduction means that for all the 4 uprights the mass was reduced with more than a knuckle. The topological optimized variant could be directly printed by SLM, being a suitable study-case for Design for Additive Manufacturing Method. However, due to the prohibitive cost of such technologies, there could be employed a less expensive variant of making a silicone rubber mould after a Fused Deposition Modelling (FDM) based model from poly-lactic acid polymer (PLA), casting a wax master model which is used for casting the Ti-6Al-4V steering knuckle, eventually machining only the functional joints.

The original contributions in this paper are largely FEM simulations in Ansys, especially topological optimization, the post-processing of the model being considered crucial to obtain not only functional parts in term of geometry, but also a fluid design which tends to come closer to natural shape design, with a striking similarity to bones, this kind of component being crucial in the skeleton of the EV presented in Chapter 1 of the present paper.

\section{References}

1. S. Bankoti, N.Jain, A,Misra, IJREST, 2, 30-35, (2015)

2. History, Formula SAE, [Online]. Available: https://www.fsaeonline.com/page.aspx?pageid=c4c5195a-60c0-46aa-acbf2958ef545b72. [Accessed 2004 2020]

3. A. Garg, IJSR, 6, pp. 1983-1988, (2017)

4. Z.Chen, Q.Chen, Nanomaterials, 2015, 1-14, (2015)

5. http://asm.matweb.com/search/SpecificMaterial.asp?bassnum=MA7075T6, [Accessed 19.05.2020]

6. C. Y. Yap, C.K. Kua, Z.L Dong, Z.H. Liu, D. Q. Zhang, L.E. Loh, S.L. Sing, Appl. Phys. Rev. 2, 041101, 1-19, (2015)

7. H. Gong, J.J.S. Dilip, L. Yang, C. Teng, B. Stucker, IOP Conf. Ser.: Mater. Sci. Eng., Influence of small particles inclusion on selective laser melting of Ti-6Al-4V powder, (Atlanta, USA, 2017)

8. Z. Wang, Z. Xyao, C. Huang, W. Zhang, Opt Laser Technol, 112, 159-167, (2019)

9. C.R. Knowles, T.Becker, R.Tait, RAPDASA'12, The effect of heat treatment on the residual stress levels within direct metal laser sintered Ti-6Al-4V as measured using the hole-drilling strain gauge method, (Sun City, South Africa, 2012)

10. D. Crola, The encyclopedia of Automotive Engineering, (Willey, Leeds. 2015)

11. M. McCune, D. Nunes, M. Patton, C. Richardson, E. Sparer, Formula SAE Interchangeable Independent Rear Suspension Design, (Cal. Poly, San Luis, 2009)

12. http://www.engineeringinspiration.co.uk/brakecalcs.html. [Accessed 21.05.2020]

13. S. I. Pedro da Silva, S. J. Idehara, SAE Brazil'18, Characterization of the Brake System of a Formula Student Vehicle, (Sao Paolo, Brazil, 2018)

14. A. Jula, "Organe de Masini si Transmisii Mecanice", (Editura Universității Transilvania, Brasov, 2004)

15. SAE International, Formula SAE 2020 Rules, https://fsaeonline.com/cdsweb/gen/DownloadDocument.aspx?DocumentID=1b6bda5 2-48d0-4286-931d-c9418165fd3e, [Accessed 22.05.2020]. 
16. http://www.fsae.com/forums/archive/index.php/t3966.html? $\mathrm{s}=5 \mathrm{ce} 42 \mathrm{bd} 67 \mathrm{e} 1 \mathrm{ff} 12 \mathrm{ad0ef134603742939}$ [Accesed 15.03.2021] 